\title{
ANALISIS FITOKIMIA DAN UJI TOTAL KAPANG PADA RUMPUT LAUT KERING Eucheuma denticulatum DAN Kappaphycus alvarezii
}

\author{
Sutardy Mayore ${ }^{1}$, Lena J. Damongilala ${ }^{2}$, Hanny W. Mewengkang ${ }^{2}$, \\ Netty Salindeho' ${ }^{2}$, Daisy M. Makapedua ${ }^{2}$, Grace Sanger ${ }^{2}$ \\ ${ }^{1)}$ Mahasiswa pada Program Studi Teknologi Hasil Perikanan FPIK UNSRAT Manado. 95115. \\ ${ }^{2)}$ Staf pengajar pada Program Studi Teknologi Hasil Perikanan FPIK UNSRAT Manado. 95115. \\ E-mail: tardimayore@yahoo.co.id
}

\begin{abstract}
The purpose of this study was to determine the phytochemistry content of dried seaweed Eucheuma denticulatum and Kappaphycus alvarezii using methanol and ethanol as solvents and to measure the total plate count (TPC) in the simplicia of dried seaweed Eucheuma denticulatum and Kappaphycus alvarezii. The results showed that dried seaweed Eucheuma denticulatum and Kappahycus alvarezii extract with ethanol and methanol contained bioactive compounds such as Flavonoids, Saponins, Tannins, Terpenoids, Phenols and Alkaloid in Dragendorf reagents and Wagner reagents. However, alkaloid was not found in Mayer reagents in both seaweed. Moreover, steroid was only identified in both seaweed extracts with ethanol. While total plate count (TPC) in incubation for two days at $25-30^{\circ} \mathrm{C}$ was $3.1 \times 10^{2} \mathrm{CFU} / \mathrm{g}$ for dried seaweed Eucheuma denticulatum and Kappaphycus alvarezii had total plate count (TPC) of $3.4 \times 10^{2} \mathrm{CFU} / \mathrm{g}$.
\end{abstract}

Keywords: Eucheuma denticulatum, Kappaphycus alvarezii, Phytochemistry, Methanol, Ethanol, Total Plate Count (TPC).

Tujuan dari penelitian ini ialah untuk mengetahui kandungan fitokimia dari rumput laut kering Eucheuma denticulatum dan Kappaphycus alvarezii menggunakan pelarut methanol dan etanol, dan untuk mengukur total kapang dalam simplisia rumput laut kering Eucheuma denticulatum dan Kappaphycus alvarezii. Hasilnya menunjukkan bahwa rumput laut kering Eucheuma denticulatum dan Kappaphycus alvarezii yang di ekstrak dengan etanol dan methanol, mengandung senyawa Flavonoid, Saponin, Terpenoid, Tanin, Fenol dan Alkaloid pada pereaksi Dragendorf dan Wagner. Senyawa Alkaloid pada pereaksi Mayer tidak teridentifikasi pada kedua rumput laut. Senyawa Steroid yang teridentifikasi pada kedua rumput laut yang diekstrak dengan etanol. Sementara itu, total kapang yang di inkubasi selama dua hari pada suhu $25-30^{\circ} \mathrm{C}$ ialah $3,1 \times 10^{2} \mathrm{CFU} / \mathrm{g}$ untuk rumput laut kering Eucheuma denticulatum, sedangkan rumput laut kering Kappaphycus alvarezii memiliki total kapang $3,4 \times 10^{2}$ $\mathrm{CFU} / \mathrm{g}$.

Kata kunci: Eucheuma denticulatum, Kappaphycus alvarezii, Fitokimia, Metanol, Etanol, Total Kapang.

\section{PENDAHULUAN}

Indonesia merupakan negara bahari yang memiliki potensi untuk membudidayakan rumput laut secara luas. Daerah penghasil rumput laut di Indonesia meliputi perairan pantai yang mempunyai paparan terumbu (reef flats), seperti Kepulauan Riau, BangkaBelitung, Seribu, Karimun Jawa, Selat Sunda, pantai Jawa bagian selatan, Bali, Nusa Tenggara Barat, Nusa Tenggara Timur, pulaupulau di Sulawesi dan Maluku (Kadi, 2004). Rumput laut mengandung berbagai unsur fitokimia unik yang tidak teridentifikasi pada tanaman terestrial. Analisis fitokimia merupakan pengujian yang digunakan untuk memberikan informasi jenis senyawa kimia yang terkandung dalam tumbuhan serta dapat memberikan efek fisiologis. Informasi mengenai komponen aktif sangat berguna untuk memprediksi manfaatnya bagi tubuh manusia (Copriyadi et al. 2005 dalam Maharany dkk., 2017). Pengujian atau pemeriksaan persyaratan parameter standar mikrobiologi, harus dilakukan pada simplisia dengan berpegang pada manajemen pengendalian mutu eksternal pada badan formal seperti Departemen Kesehatan. Menurut Depkes RI., (2000) tujuan dari uji total kapang adalah untuk memberikan jaminan bahwa sediaan simplisia tidak mengandung cemaran fungi melebihi batas ditetapkan karena 
berbahaya bagi kesehatan. Penelitian ini bertujuan untuk mengetahui kandungan fitokimia rumput laut Eucheuma denticulatum dan Kappaphycus alvarezii yang telah dikeringkan oleh petani rumput laut di desa Arakan Minahasa Selatan, Sulawesi Utara dan menghitung total kapang pada rumput laut tersebut.

\section{METODE PENELITIAN}

\section{Metode Penelitian}

Penelitian ini dilakukan secara kualitatif melalui analisis fitokimia dengan ekstrak metanol dan etanol dan secara kuantitatif melalui uji total kapang dari rumput laut kering Eucheuma denticulatum dan Kappaphycus alvarezii.

\section{Bahan dan Alat}

Bahan baku penelitian berupa Eucheuma denticulatum dan Kappaphycus alvarezii kering yang didapat dari desa Arakan Minahasa Selatan. Bahan untuk ekstraksi dan uji fitokimia berupa Etanol 96\% dan metanol 95\%, akuades, $\mathrm{H}_{2} \mathrm{SO}_{4}$, pereaksi Dragendorff, pereaksi Mayer, Wagner, kloroform, asam asetat glasial, $\mathrm{FeCl}_{3}$, $\mathrm{HCl}$ pekat, $\mathrm{NaOH}$, serbuk magnesium. Sedangkan bahan untuk uji total kapang berupa $\mathrm{NaCl}$, Potato Dextrose Agar, Alkohol 70\%.

Alat yang digunakan untuk ekstraksi dan analisa fitokimia antara lain: Galon, Kertas Whatman no. 42, Erlenmeyer $1000 \mathrm{ml}$, labu ukur, vakum rotary evaporator, dan inkubator. Sedangkan untuk uji angka kapang yaitu: Autoklaf, awan petri, Erlenmeyer 1000 ml, Erlenmeyer $250 \mathrm{ml}$, gelas ukur $1000 \mathrm{ml}$, stiring hotplate, inkubator dan timbangan digital.

\section{Prosedur Penelitian}

Pengambilan dan Preparasi Eucheuma denticulatum dan Kappaphycus alvarezii

Sampel rumput laut diambil dari petani pembudidaya dalam bentuk kering. Rumput laut kering dicuci dengan menggunakan air tawar untuk menghilangkan kotoran, garam dan debu. Sampel dikeringkan dengan cara diangin-anginkan dalam ruangan kurang lebih selama 3 hari. Rumput laut dipotong-potong sampai halus dengan menggunakan gunting, lalu ditimbang sebanyak 500g kemudian dimasukkan dalam kantong plastik dan diberi label.

\section{Proses Pembuatan Ekstrak}

Langkah-langkah ekstraksi sampel mengacu pada penelitian Damongilala (2014) yang telah dimodifikasi.
Rumput laut Eucheuma denticulatum dan Kappaphycus allvarezii kering dicuci bersih dan dikeringkan.

Eucheuma denticulatum dan Kappaphycus alvarezii dipotong-potong kecil dan ditimbang sebanyak $500 \mathrm{~g}$, lalu dimasukkan ke dalam masing-masing toples, kemudian ditambahkan pelarut metanol dan etanol di setiap toples dengan perbandingan 1:2(b/v).

Maserasi selama 3x24 jam. Hasil maserasi kemudian disaring dengan kertas saring Whatman no. 42 sehingga dihasilkan filtrat dan residu. Filtrat disimpan untuk perlakuan selanjutnya.

Filtrat dievaporasi dengan vakum rotary evaporator pada suhu $40^{\circ} \mathrm{C}$ hingga diperoleh ekstrak kental. Ekstrak kental yang diperoleh di-desalting dan selanjutnya dilakukan uji fitokimia.

\section{Uji Kandungan Fitokimia}

Uji kandungan fitokimia ini mengacu pada penelitian Sangi, $d k k$., (2008).

\section{Uji senyawa flavonoid}

Sampel rumput laut kering sebanyak $2 \mathrm{~g}$ diekstrak dengan $5 \mathrm{ml}$ etanol dan dipanaskan selama 5 menit di dalam tabung reaksi. Selanjutnya ditambah beberapa tetes $\mathrm{HCl}$ pekat. Kemudian ditambahkan 0,2g serbuk magnesium. Sampel positif mengandung flavonoid jika terbentuk warna orange hingga merah.

\section{Uji senyawa saponin}

Sampel rumput laut kering sebanyak $2 \mathrm{~g}$ dimasukkan ke dalam tabung reaksi kemudian ditambahkan akuades hingga larutan terendam, didihkan selama 2 menit kemudian didinginkan dan larutan dikocok kuat-kuat. Sampel positif mengandung senyawa saponin apabila terbentuk busa yang permanen yang tidak hilang dalam waktu 15 menit.

\section{Uji senyawa alkaloid}

Sampel rumput laut kering sebanyak $2 \mathrm{~g}$ ditambahkan kloroform secukupnya, selanjutnya ditambahkan $10 \mathrm{ml}$ amoniak dan $10 \mathrm{ml}$ kloroform. Kemudian larutan disaring ke dalam tabung reaksi dan filtrat ditambahkan 10 tetes $\mathrm{H}_{2} \mathrm{SO}_{4}$. Campuran dikocok dengan teratur, dibiarkan beberapa menit sampai terbentuk 2 lapisan. Lapisan atas dipindahkan ke dalam tiga tabung reaksi masing-masing sebanyak $1 \mathrm{ml}$. 
Kemudian masing-masing tabung tersebut ditambahkan beberapa tetes pereaksi Mayer, Wagner dan Dragendorf. Apabila terbentuk endapan menunjukkan bahwa sampel tersebut mengandung alkaloid, dengan pereaksi Mayer memberikan endapan putih, dengan pereaksi Wagner memberikan endapan berwarna cokelat dan pereaksi Dragendorf memberikan endapan berwarna jingga.

\section{Uji senyawa steroid dan terpenoid}

Sampel rumput laut kering sebanyak $2 \mathrm{~g}$ ditambahkan asam asetat glasial sampai semua sampel terendam, dibiarkan selama 15 menit kemudian 6 tetes larutan dipindahkan ke dalam tabung reaksi dan ditambahkan 2-3 tetes asam sulfat pekat. Adanya terpenoid ditunjukkan dengan terjadinya warna merah, jingga atau ungu, sedangkan steroida ditunjukkan dengan terbentuknya warna biru.

\section{Uji senyawa fenolik}

Sebelum melakukan identifikasi senyawa fenolik terlebih dahulu dilakukan ekstraksi secara kontinu menggunakan alat soxhlet dengan pelarut eter untuk melarutkan lemak dan klorofil yang terdapat pada daun sukun. Hasil ekstrak eter berwarna hijau kehitaman, bila direaksikan dengan $\mathrm{FeCl}_{3} \quad 5 \%$ tidak dapat bereaksi sehingga pada ekstrak eter tidak mengandung senyawa fenol. Setelah diekstraksi dengan eter kemudian diekstraksi dengan methanol $90 \%$ dan dilanjutkan dengan metanol $50 \%$ untuk mengikat komponen-komponen yang bersifat polar. $1 \mathrm{ml}$ ekstrak methanol ditambah $\mathrm{FeCl}_{3} 5 \%$ terjadi perubahan warna dari kuning kecoklatan menjadi coklat orange yang menunjukkan adanya senyawa fenolik.

\section{Uji Total Kapang}

Uji Total Kapang adalah satu parameter keamanan dari simplisia rumput laut kering Eucheuma denticulatum dan Kappaphycus alvarezii. Total Kapang menunjukan adanya cemaran kapang dalam sediaan yang diperiksa. Uji angka kapang dilakukan dengan cara yaitu:

Aquades $700 \mathrm{ml}$ dituang pada gelas ukur $1000 \mathrm{ml}$, lalu tuang kembali pada aquades tersebut ke erlen meyer ukuran $1000 \mathrm{ml}$.

Penimbangan Potato Dextrose Agar sebanyak $14 \mathrm{~g}$ dan dimasukkan ke dalam erlenmeyer yang sudah berisi akuades sebanyak $700 \mathrm{ml}$.
Media dihomogenkan dengan menggunakan stiring hotplate sampai media benarbenar tercampur.

$\mathrm{NaCl}$ 0,9\% dimasukkan ke dalam gelas ukur $1000 \mathrm{ml}$ sebanyak $225 \mathrm{ml}$ lalu dimasukkan kembali ke erlen meyer ukuran $250 \mathrm{ml}$.

Sebanyak 16 tabung reaksi diisi masingmasing dengan $\mathrm{NaCl} 0,9 \%$ sebanyak $9 \mathrm{ml}$.

Alat dan Bahan yang akan digunakan di masukkan terlebih dahulu ke dalam autoclave untuk disterilkan dengan suhu $121^{\circ} \mathrm{C}$.

Sementara beberapa alat dan bahan disterilkan, persiapkan laminarflow, ruangan dan alat secara aseptik.

Sampel rumput laut kering sebanyak $25 \mathrm{~g} / \mathrm{sampel}$. Sampel ini dimasukkan ke dalam erlen meyer ukuran $250 \mathrm{ml}$ yang telah diisi dengan $\mathrm{NaCl} 0,9 \%$.

Siapkan alat dan bahan yang sudah di sterilkan dari autoclave ke laminarflow kemudian dilakukan pengenceran. Pipet masing-masing $1 \mathrm{ml}$ dari pengenceran $10^{-1}$ sampai $10^{-4}$ secara aseptik ke dalam cawan petri steril.

Tuangkan $9 \mathrm{ml}$ Potato Dextroxe Agar yang masih cair dengan suhu $45^{\circ} \mathrm{C} \pm 1^{\circ} \mathrm{C}$ ke dalam masing-masing cawan petri.

Cawan petri goyangkan secara hati-hati sehingga contoh dan pembenihan tercampur rata.

Semua cawan petri yang sudah berisi sampel kemudian diinkubasi selama 2 hari dengan suhu inkubasi $25-30^{\circ} \mathrm{C}$.

\section{HASIL DAN PEMBAHASAN}

\section{Analisis Fitokimia}

Komponen yang terdapat dalam ekstrak metanol dan etanol rumput laut kering Eucheuma denticulatum dan Kappaphycus alvarezii dianalisis memakai beberapa pereaksi untuk melihat adanya golongan senyawa alkaloid, flavonoid, tanin, steroid, triterpenoid dan fenol.

Hasil Analisis Fitokimia Rumput Laut Kering Eucheuma denticulatum dan Kappaphycus alvarezii Ekstrak Etanol dan Metanol disajikan pada Tabel 1.

Identifikasi yang dilakukan pada sampel rumput laut kering Eucheuma denticulatum dan Kappaphycus alvarezii ekstrak etanol dan metanol menunjukkan adanya senyawa Flavonoid dengan perubahan warna menjadi jingga, senyawa Saponin dengan adanya busa yang bertahan selama 10 menit, senyawa Terpenoid dengan perubahan warna menjadi 
merah, senyawa Tanin dengan perubahan warna hijau kehitaman, senyawa Fenol dengan perubahan warna menjadi cokelat orange, senyawa Alkaloid pada pereaksi Dragendorf dengan adanya endapan berwarna jingga dan pada pereaksi Wagner membentuk endapan berwarna cokelat. Senyawa yang tidak teridentifikasi pada rumput laut kering yaitu senyawa Steroid dan Alkaloid pada pereaksi Mayer ekstrak Metanol, sedangkan pada ekstrak etanol hanya senyawa Alkaloid pada pereaksi Mayer yang tidak teridentifikasi.

Tabel 1. Hasil Analisis Fitokimia Rumput Laut Kering Eucheuma denticulatum Ekstrak Ethanol dan Metanol.

\begin{tabular}{|c|c|c|c|c|c|c|}
\hline \multirow{3}{*}{ No } & \multirow{3}{*}{$\begin{array}{c}\text { Nama } \\
\text { Senyawa }\end{array}$} & \multirow{3}{*}{$\begin{array}{l}\text { Metode } \\
\text { Uji }\end{array}$} & \multicolumn{4}{|c|}{ Hasil Uji } \\
\hline & & & \multicolumn{2}{|c|}{$\begin{array}{c}\text { Eucheuma } \\
\text { denticulatum }\end{array}$} & \multicolumn{2}{|c|}{$\begin{array}{c}\text { Kappaphycus } \\
\text { alvarezii }\end{array}$} \\
\hline & & & Etanol & Metanol & Etanol & Metanol \\
\hline 1 & Flavonoid & $\begin{array}{l}\text { Pereaksi HCL } \\
\text { pekat }+\mathrm{Mg}\end{array}$ & + & + & + & + \\
\hline 2 & Saponin & Pereaksi Aquades & + & + & + & + \\
\hline \multirow[t]{3}{*}{3} & Alkaloid & $\begin{array}{l}\text { a. Pereaksi } \\
\text { Dragendorff }\end{array}$ & + & + & + & + \\
\hline & & $\begin{array}{l}\text { b. Pereaksi } \\
\text { Wagner }\end{array}$ & + & + & + & + \\
\hline & & c. Pereaksi Mayer & - & - & - & - \\
\hline 4 & Steroid & $\begin{array}{l}\text { Pereaksi asam } \\
\text { asetat }+ \text { HCL } \\
\text { pekat }\end{array}$ & + & - & + & - \\
\hline 5 & Terpenoid & $\begin{array}{l}\text { Pereaksi asam } \\
\text { asetat + HCL } \\
\text { pekat }\end{array}$ & + & + & + & + \\
\hline 6 & Tanin & $\begin{array}{l}\text { Pereaksi } \mathrm{FeCl} 3 \\
1 \% \text {. }\end{array}$ & + & + & + & + \\
\hline 7 & Fenol & $\begin{array}{l}\text { Pereaksi } \mathrm{FeCl} 3 \\
5 \%\end{array}$ & + & + & + & + \\
\hline
\end{tabular}

Penelitian sebelumnya oleh Sari, $d k k$, (2015) skrining fitokimia rumput laut Eucheuma denticulatum ekstrak etanol dinyatakan bahwa senyawa seperti triterpenoid, alkaloid, dan flavonoid teridentifikasi dan hanya senyawa tannin dan steroid tidak teridentifikasi. Menurut Lantah, dkk., (2017) bahwa proses pengeringan dengan sinar matahari dan proses desalting yang kurang baik dapat berpengaruh terhadap hasil analisis. Ini menyebabkan senyawa-senyawa bioaktif pada rumput laut kering Kappaphycus alvarezii ekstrak metanol tidak teridentifikasi. Sedangkan dalam penelitian ini, hanya senyawa alkaloid pada pereaksi mayer saja yang tidak teridentifikasi. Ini disebabkan perbedaan pemasokan bahan baku seperti rumput laut dan proses desalting yang dilakukan berbeda.

\section{Total Angka Kapang}

Kapang merupakan salah satu jenis mikroba yang banyak dijumpai pada produk olahan termasuk produk perikanan. Kapang mempunyai ciri khas seperti filament, itulah yang membedakan kapang dengan khamir. Total angka kapang pada pada penelitian dengan sampel rumput laut kering Eucheuma denticulatum dan Kappaphycus alvarezii bisa dilihat pada Tabel 2.

Tabel 2. Hasil Uji Angka Kapang pada Rumput Laut Kering Eucheuma denticulatum dan Kappaphycus alvarezii.

\begin{tabular}{ll}
\hline \multicolumn{1}{c}{ Sampel } & Total Kapang \\
\hline Eucheuma denticulatum & $3,1 \times 10^{2} \mathrm{CFU} / \mathrm{g}$ \\
Kappahycus alvarezii & $3,4 \times 10^{2} \mathrm{CFU} / \mathrm{g}$ \\
\hline
\end{tabular}

Hasil dari total kapang untuk rumput laut kering Eucheuma denticulatum adalah $3,1 \times 10^{2} \mathrm{CFU} / \mathrm{g}$ sedangkan untuk rumput laut

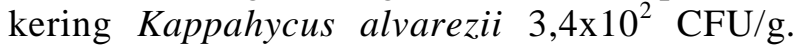
Hasil uji tersebut dibandingkan dengan SNI (2009) yang memiliki nilai total kapang sebesar $1 \times 10^{2} \mathrm{CFU} / \mathrm{g}$ bisa disimpulkan bahwa rumput laut kering Eucheuma denticulatum dan Kappahycus alvarezii masih memiliki total kapang yang aman karena masih dalam satu log yang sama dengan SNI.

Penyebab tumbuhnya mikroba dipengaruhi oleh faktor lingkungan (Musa, $d k k$., 2017). Penanganan yang kurang baik dari petani rumput laut yang ada di Desa Arakan Minahasa Selatan menyebabkan menurunnya kualitas rumput laut tersebut. Penangan kurang baik yang dimaksudkan disini ialah proses penjemuran yang tidak menentu dan tidak terkontrol sehingga menyebabkan adanya air hujan maupun debu yang bisa saja tercampur pada rumput laut dan proses penyimpanan yang tidak mementingkan kebersihan rumput laut. Rumput laut hanya disimpan pada karung dan dibiarkan selama kurun waktu yang tidak menentu atau hingga ada pembeli yang datang. Hal inilah yang menyebabkan timbulnya koloni kapang pada rumput laut. Dari hasil penelitian Teurupun, dkk., (2013) bahwa total angka kapang pada rumput laut kering Kappaphycus alvarezii berkisar antara $2,0 \times 10^{3}-3,0 \times 10^{3}$ $\mathrm{CFU} / \mathrm{g}$ dengan total angka kapang tertinggi $3,0 \times 10^{3} \mathrm{CFU} / \mathrm{g}$, ini menandakan bahwa rumput laut Kappaphycus alvarezii gampang ditumbuhi kapang. 


\section{KESIMPULAN DAN SARAN}

\section{Kesimpulan}

1. Identifikasi pada rumput laut kering Eucheuma denticulatum dan Kappahycus alvarezii dengan ekstrak etanol teridentifikasi senyawa Flavonoid, Saponin, Tanin, Terpenoid, Steroid, Fenol dan senyawa Alkaloid pada pereaksi Dragendorf dan pereaksi wagner. Senyawa Alkaloid tidak teridentifikasi pada pereaksi mayer. Identifikasi pada rumput laut kering Eucheuma denticulatum dan Kappaphycus alvarezii dengan ekstrak metanol teridentifikasi senyawa Flavonoid, Saponin, Tanin, Terpenoid, Fenol dan senyawa Alkaloid pada pereaksi Dragendorf dan pereaksi Wagner. Senyawa yang tidak teridentifikasi hanyalah senyawa steroid dan senyawa alkaloid pada pereaksi Mayer.

2. Uji total kapang pada 2 hari inkubasi dalam oven dengan suhu $20-30^{\circ} \mathrm{C}$ dari rumput laut kering Eucheuma denticulatum memiliki total kapang lebih kecil yaitu $3,1 \times 10^{2}$ sedangkan untuk Kappaphycus alvarezii yaitu $3,4 \times 10^{2}$.

\section{Saran}

1. Perlu dilakukan kembali penelitian tentang analisis fitokimia pada rumput laut kering jenis yang lain dengan menggunakan pelarut metanol dan etanol, agar supaya dapat diketahui jenis rumput laut apa saja yang memiliki senyawa metabolit sekunder seperti flavonoid, alkaloid, tannin, steroid dan triterpenoid serta fenol.

2. Perlu penelitian lanjut untuk melihat jenis kapang yang tumbuh pada rumput laut kering Eucheuma denticulatum dan Kappaphycus alvarezii.

\section{DAFTAR PUSTAKA}

Departemen Kesehatan RI. 2000. Parameter Standar Umum Ekstrak Tumbuhan Obat. Direktoral Jendral Pengawasan Obat dan Makanan, Direktorat Pengawasan Obat Tradisional, Jakarta, Hal 31-32

Kadi, A. 2004. Potensi Rumput Laut Di Beberapa Perairan Pantai Indonesia. Oseana. Vol. XXIX, No 4

Maharany, F. Nurjanah, Suwandi, R. Anwar, E. Hidayat, T. 2017. Kandungan Senyawa Bioaktif Rumput Laut Padina australis dan Eucheuma cottonii Sebagai Bahan Baku Krim Tabir Surya. Jurnal. IPB. Bogor. JPHPI 2017, Volume 20 Nomor 1

Musa, S. Sanger, G. Dien, H. A. 2017. Komposisi Kimia Senyawa Bioaktif dan Angka Lempeng Total pada Rumput Laut Gracilaria edulis Jurnal Media Teknologi Hasil Perikanan. Vol. 5, No. 3,

Sangi M, Runtuwene, M, R, J, Simbala, H, E, I, Makang, V. M, A. 2008. Analisis Fitokimia Tumbuhan Obat Di Kabupaten Minahasa Utara. UNSRAT. Chem. Prog. Vol. 1:

Sari, B. 1, Susanti, N. Sutanto. 2015. Skrining Fitokimia dan Aktivitas Antioksidan Fraksi Etanol Alga Merah Eucheuma spinosum. FMIPA. Universitas Pakuan. Bogor

Teurupun, A. Timbowo, S. M. Palenewen, J. 2013. Identifikasi Kapang Pada Rumput Laut Eucheuma cotonii (Kappaphycus alvarezii) Kering Dari Desa Rap Rap Arakan Kecamatan Tatapan Kabupaten Minahasa Selatan. Jurnal Media Teknologi Hasil Perikanan. UNSRAT. Manado. Vol. 1:1 